\section{Mustard Cover Crop Growth and Weed Suppression in Organic, Strawberry Furrows in California}

\author{
Eric B. Brennan ${ }^{1}$ \\ U.S. Department of Agriculture, Agricultural Research Service, U.S. \\ Agricultural Research Station, 1636 E. Alisal Street, Salinas, CA 93905
}

Richard F. Smith

University of California Cooperative Extension, Monterey County, 1432 Abbott Street, Salinas, CA 93901

Additional index words. strawberry production, weed management, runoff, soil erosion, plastic mulch, plasticulture, organic farming

\begin{abstract}
Strawberry (Fragaria $\times$ ananassa Duch.) production in California uses plastic mulch-covered beds that provide many benefits such as moisture conservation and weed control. Unfortunately, the mulch can also cause environmental problems by increasing runoff and soil erosion and reducing groundwater recharge. Planting cover crops in bare furrows between the plastic cover beds can help minimize these problems. Furrow cover cropping was evaluated during two growing seasons in organic strawberries in Salinas, CA, using a mustard (Sinapis alba $\mathrm{L}$.) cover crop planted at two seeding rates $(1 \times$ and $3 \times$ ). Mustard was planted in November or December after strawberry transplanting and it resulted in average densities per meter of furrow of 54 and 162 mustard plants for the $1 \times$ and $3 \times$ rates, respectively. The mustard was mowed in February before it shaded the strawberry plants. Increasing the seeding rate increased mustard shoot biomass and height, and reduced the concentration of $P$ in the mustard shoots. Compared with furrows with no cover crop, cover-cropped furrows reduced weed biomass by $29 \%$ and $40 \%$ in the $1 \times$ and $3 \times$ seeding rates, respectively, although weeds still accounted for at least $28 \%$ of the furrow biomass in the cover-cropped furrows. These results show that growing mustard cover crops in furrows without irrigating the furrows worked well even during years with relatively minimal precipitation. We conclude that 1 ) mustard densities of $\approx 150$ plants $/ \mathrm{m}$ furrow will likely provide the most benefits due to greater biomass production, $\mathrm{N}$ scavenging, and weed suppression; 2) mowing was an effective way to kill the mustard; and 3) high seeding rates of mustard alone are insufficient to provide adequate weed suppression in strawberry furrows.
\end{abstract}

Strawberries are the most economically important fruit in the central coast region of California with a value of $\$ 953.7$ million from 13,073 acres in Monterey and Santa Cruz counties (Monterey County Agricultural Commissioner, 2016; Santa Cruz County Agricultural Commissioner, 2016); in contrast, lettuce was the most economically important vegetable in these counties with a value of $\$ 1.28$ billion from 110,559 acres. In contrast to bare beds used for vegetable production, strawberry beds in this region are covered in plastic mulch to suppress weeds, conserve soil moisture, reduce fruit decay, and regulate bed temperature, which in turn impacts growth and fruit production (Strand, 2008). But unfortunately,

\footnotetext{
Received for publication 5 Oct. 2017. Accepted for publication 18 Dec. 2017.

We thank Rogelio Fuentes and the crew at Fuentes Berry Farms, Laura Murphy, Patricia Love, and Gustavo Reyes for their assistance with fieldwork. We also thank Michael Cahn, Richard Rosecrance, and Jim Leap for their review of the manuscript. ${ }^{1}$ Corresponding author. E-mail: eric.brennan@ars. usda.gov.
}

the mulch can create serious environmental problems during winter storms by concentrating rainfall into the furrow between beds that accelerates runoff and reduces the infiltration needed to recharge the groundwater, the sole source of irrigation and drinking water in this region. Some of the highest soil erosion rates in the western United States have been reported in strawberry fields in the central coast region of California (Mountjoy, 2012). Storm runoff from plastic-mulched fields also increases the potential movement of pesticides, sediments, and nutrients into surface waters and the ocean. For example, $\approx 77 \%$ of the soil surface is covered in plastic mulch in a field with 132-cm-wide beds (furrow center to center). Even in a field with a relatively small slope of $1 \%$, this can create serious runoff problems (Fig. 1).

Growing cover crops in the normally bare furrow bottoms of strawberry and vegetable fields has been proposed as a possible strategy to minimize the loss of nutrients, sediments, and pesticides (Brennan, 2017; Cahn et al., 2006a, 2006b; Rice et al., 2004). In an organic strawberry field with a $2 \%$ slope in California's central coast region, a barley (Hordeum vulgare L.) cover crop reduced total nitrogen by $47 \%$, phosphorous by $44 \%$, sediment by $69 \%$, and turbidity by $71 \%$ in runoff compared with bare, hand-weeded furrows (Cahn et al., 2006a). Although grass-selective herbicides provide an effective way to kill cereal cover crops in conventional strawberries, mechanical control (tillage or mowing) is the only option available to organic strawberry growers and can be difficult with grasses because of their ability to reroot when tilled in wet conditions, and regrow after mowing (Smith et al., 2015). Despite the clear environmental benefits of cover cropping in strawberry furrows, adoption of cover cropping is low in this region. However, this situation may change with increasing regulatory pressure on growers from programs such as the Irrigated Lands Regulatory Program (California Environmental Protection Agency).

An ideal cover crop for strawberry furrows of California would 1) be easy and inexpensive to establish; 2) reduce erosion, runoff, nitrate leaching, and weeds; 3 ) not compete with strawberries; 4) be easy to kill; 5) not harbor pests; 6) increase beneficial insect conservation; and 7) produce residue that is easy to manage and that does not hinder transplanting, weeding, and harvesting.

Research on reduced tillage systems for organic vegetables found that hollowstemmed mustard cover crops such as $S$. alba ('IdaGold') grown in furrows were relatively easy to kill mechanically when they were crushed by tractor wheels or mowed (Brennan, unpublished data, 2008). This finding indicated that mustard might be a good option for cover cropping in organic strawberry furrows and inspired the experiment reported here. The objective of the experiment was to evaluate the effect of 'IdaGold' mustard seeding rate on mustard population density, biomass production, plant height, nutrient concentration, and weed suppression. We expected that higher seeding rates would provide some benefits in furrow cover crops by increasing early-season biomass production, nutrient uptake, and weed suppression.

\section{Materials and Methods}

Site description, field preparation, and experimental design

The experiment occurred in commercialscale organic strawberry fields at the USDAARS organic research farm in Salinas, CA (lat. 36.622658, long. -121.549172 , elevation $37 \mathrm{~m}$ ) located $\approx 25 \mathrm{~km}$ inland from the Monterey Bay. The soil is a Chualar loamy sand (fine-loamy, mixed, and thermic Typic Argixerol) with $\approx 77 \%$ sand, $15 \%$ silt, and $8 \%$ clay in fields with a slope of $\approx 1 \%$ perpendicular to the direction of the strawberry beds. The strawberry beds were made with a GPS-guided tractor and were oriented in the northwest to southeast direction with a $130^{\circ}$ to $320^{\circ} \mathrm{N}$ bearing. The $36-38-\mathrm{cm}$ high beds were $122-\mathrm{cm}$ wide (furrow center to furrow center) in Year 1 and 132-cm wide in Year 2 . The bed top width was $\approx 61$ and 


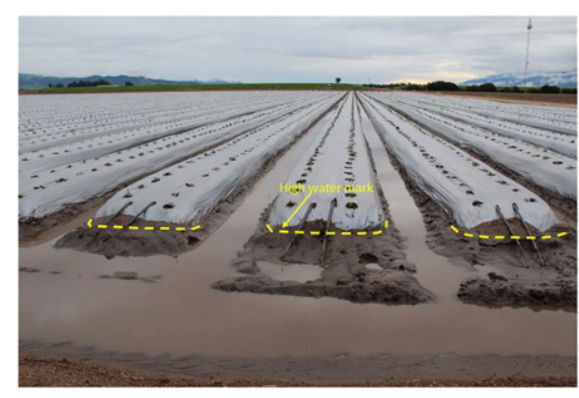

Fig. 1. Saturated furrow bottoms and runoff from bare furrows in a commercial-scale organic strawberry field at the USDA-ARS in Salinas, CA. The plastic mulch-covered beds are $132-\mathrm{cm}$ wide (furrow center to furrow center) and are $\approx 100$-m long. The slope at this site is $\approx 1 \%$ perpendicular to the bed direction. The field drains toward the bottom of the photograph and then exits to the right toward the Salinas River which flows to the Monterey Bay. This bay has been a National Marine Sanctuary of the United States since 1992. The photograph was taken on 12 Dec. 2014 several hours after a 10-mm rain storm had occurred earlier that day. This illustrates the problem of plastic mulch concentrating rainfall, sediment, and nutrient laden runoff into the furrows. The dashed lines indicate the approximate high water mark on the ends of the beds.

$66 \mathrm{~cm}$ in Years 1 and 2, respectively. Plastic mulch (Poly-Ag Corp, San Diego, CA) colored silver on the upper side and black on the underside covered the bed top and sides, and left bare furrow bottoms that were $\approx 30-\mathrm{cm}$ wide; this color of mulch is common in organic and conventional strawberry production in this region. The furrow bottom area represented $25 \%$ of the land area in Year 1 $(30 \mathrm{~cm} / 122 \mathrm{~cm}=25 \%)$ vs. $23 \%$ of the area in Year $2(30 \mathrm{~cm} / 132 \mathrm{~cm}=23 \%)$. The mulch was applied from 152- to 168 -cm-wide rolls with a custom mulch layer that extended the edges of the mulch below the soil surface to hold it in place. The bed tops contained two lines of drip tape on the soil surface under the mulch. Holes were punched through the mulch, and strawberries ('San Juan' variety) were transplanted on the bed tops in two rows $30-\mathrm{cm}$ apart in Year 1 and $41-\mathrm{cm}$ apart in Year 2 at a spacing of $25 \mathrm{~cm}$ between plants on 28 Oct. (Year 1) and 1 Nov. (Year 2). Following transplanting, the strawberries received $\approx 4 \mathrm{~mm}$ of drip irrigation every other day for 2 weeks and then as needed depending on the rainfall. Typical amounts of water applied during dry conditions were 60-70 $\mathrm{mm}$ during the first 8 weeks after transplanting. The Year 1 field had been certified organic since 2005 and the Year 2 field had been certified since 1999. Both fields were certified organic by California Certified Organic Farmers to the USDA National Organic Program standards. The fields had been in either vegetable, strawberry, or cover crop trials for 10 years before the experiment.

The experimental design was a randomized complete block with two seeding rate treatments $(1 \times$ vs. $3 \times)$ during Year 1 and three seeding rate treatments during Year 2 (no cover crop, $1 \times$, and $3 \times$ ). There were four and six replications in Years 1 and 2, respectively. The $3 \times$ seeding rate was $\approx 3-4$ times greater than the $1 \times$ rate. The $1 \times$ rate was $\approx 42-37 \mathrm{~g}$ of seed per 100 of furrow in Years 1 and 2, respectively (see additional planting details described later in the article); thus, with $122-\mathrm{cm}$ wide beds, the $1 \times$ seeding rate was $\approx 3-3.4 \mathrm{~kg} \cdot \mathrm{ha}^{-1}$. The mustard cover crop treatments were planted on $16 \mathrm{Dec}$. and 22 Nov. for Years 1 and 2, respectively. During Year 1, the treatment plots were single furrows between two strawberry beds that were randomly assigned to either of the seeding rates, whereas during Year 2, the treatment plots were pairs of furrows on either side of a bed. The beds were $\approx 18-\mathrm{m}$ long during Year 1 and 50-m long during Year 2.

Year 1 planting, management, and data collection. During Year 1, a Cole Planet Jr hand seeder (Cole Planter Company, Albany, GA) with a 10-cm-wide scatter shoe was used to plant the furrow bottoms at the target seeding rates. The planter seed plate hole no. 7 was used for the $1 \times$ rate and hole no. 14 was used for $3 \times$ rate. The $1 \times$ and $3 \times$ rates delivered $\approx 42$ and $158 \mathrm{~g}$ of seed per $100 \mathrm{~m}$ of furrow bottom, respectively. Although the higher rate delivered $\approx 3.8$ times more seed, the resulting population density was closer to three times greater in the higher rate in both years. On 5 Jan. 2012, weeds that had germinated in the holes in the mulch where the strawberries were transplanted were pulled by hand, and a long-handled wire weeder (Johnny's Select Seeds, Fairfield, MA) was used to control the relatively few weeds in the furrow along the plastic mulch, taking care not to step on the mustard seedlings.

On 9 Feb. 2012 (Year 1), the density of the mustard plants in the furrows in both treatments was determined by counting emerged plants in a 50-cm-long section along the entire width of the furrow bottom. Cover crop biomass was determined on 9 Feb. by harvesting mustard plants from $1-\mathrm{m}$ sections of the furrow bottom by hand-clipping the plants at the soil surface. Three plants among the harvested plants from each plot were randomly selected, and the shoot length from the soil surface to the apical tip and from the soil surface to the first true leaf node were measured. The harvested biomass was ovendried at $65^{\circ} \mathrm{C}$ until the weight had stabilized and weighed to determine shoot biomass production which was then used to calculate biomass production per meter of furrow bottom, rather than per unit area as is more typical in cover crop experiments. This approach was used to simplify comparisons between years where the furrow area differed slightly because of differences in bed width. Mustard shoot analyses for Year 1 were carried out at the University of California Analytical Laboratory in Davis. The dry matter (DM) samples were ground to pass through a $0.250-\mathrm{mm}$ screen, and a subsample was analyzed with the combustion gas analyzer method (Association of Analytical Communities, 1997) for total C and N (http:// anlab.ucdavis.edu/using-the-lab/analysis/ plant/522) using a TruSpec $\mathrm{CN}$ analyzer (LECO Corporation, St. Joseph, MI). The tissue was also analyzed for total phosphorous and potassium using the nitric acid/ hydrogen peroxide microwave digestion method (http://anlab.ucdavis.edu/using-thelab/analysis/plant/590) and determined by Inductively Coupled Plasma Atomic Emission Spectrometry. The reported concentrations of nutrient analyses were on a $100 \%$ DM basis from samples dried to $105{ }^{\circ} \mathrm{C}$. However, to calculate $\mathrm{N}$ accumulation in $\mathrm{kg} \cdot \mathrm{ha}^{-1}$, the concentrations were adjusted because DM per hectare was on $98 \%$ DM basis from drying at $65^{\circ} \mathrm{C}$.

Year 2 planting, management, and data collection. The Year 2 planting occurred in a field where the strawberries had been transplanted on 1 Nov. The mustard cover crop was planted on 22 Nov., and the plots were both furrows on either side of a strawberry bed that were randomly assigned to one of the seeding rates or a bare furrow treatment where cover crops were not planted. A hand-pushed Clean Seeder AP (Jang Automation Company, Korea) with no. 11 sprockets and the R12 seed wheel was used to plant the mustard. To achieve the $1 \times$ seeding rate, a mixture of $1 / 3$ viable and $2 / 3$ killed seed was planted; the seed was killed by microwaving it for $4-5 \mathrm{~min}$ and allowing it to cool before mixing it with the viable seed. The amount of live seed planted per meter of furrow was $\approx 37 \mathrm{~g}$ and $112 \mathrm{~g}$ in the $1 \times$ and $3 \times$ seeding rates, respectively. In contrast to Year 1, weeds that germinated in the furrow bottoms along the plastic mulch after mustard planting were not controlled by hoeing. Cover crop and weed biomass were harvested on 31 Jan. 2014 from 1-m lengths of furrow bottom on both sides of the bed by clipping the biomass off at the soil surface. The biomass of weed and mustard was separated and dried at $65^{\circ} \mathrm{C}$ until the weights were stabilized. Biomass production per meter of furrow bottom was the average biomass harvested from the subsamples from both furrow bottoms in each plot. On 1 Feb. 2014, the height of the tallest mustard plants in both furrows of each replicate near the plot center was measured from the ground to the apical tip. On 4 Feb. 2014, the height from the cotyledon leaf scar to the first true leaf bud was measured from three randomly chosen plants in one furrow of each plot.

On 9 Feb. 2012 (Year 1) and 13 Feb. 2014 (Year 2) the mustard and weeds were cut off near the soil surface with a Stihl or Honda gasoline-powered string trimmer (also known as a "weed wacker").

\section{Statistical analysis}

The data were analyzed using SAS version 9.4 (SAS Inst., Cary, NC) and focused on 
using 95\% confidence intervals (CIs) of the treatment means and their paired differences (i.e., effect sizes). The formula for the $\mathrm{CI}$ is an $\overline{\mathrm{X}} \pm t_{(n-1)} \frac{s}{\sqrt{ } n}$, where $t$ is the critical value from tables of the $t$ statistic that varies with the sample size of $n$ and the chosen confidence level and $s$ is the SD. This approach helped us to make practical inferences about our results and their reproducibility (Cumming, 2012; Kirk, 1996) and was chosen because of criticisms of null-hypothesis significance testing (Anderson et al., 2000; Campbell et al., 2015; Fidler et al., 2006; Hubbard and Lindsay, 2008; Lambdin, 2012; Loftus, 1996; Nakagawa and Cuthill, 2007) that can easily lead to misinterpretations of results and dichotomous thinking (i.e., statistically significant or not). To compare two treatments we focused on the proximity of the CI of their paired difference with zero whereby CIs that are further from zero provide more evidence of a true effect. If the 95\% CI of the difference does not include zero the $P<0.05$, and $P=0.05$ when one of the limits is just at zero. We mention the relationship between $P$ values and CIs as a point of reference because agricultural researchers are often unfamiliar with using CIs to make inferences about data. We encourage readers to visualize a CI in a "cat's eye" shape which is "fattest" in the center (to represent the most plausible estimate) and narrow on the ends of the CI (indicating less plausibility) (Cumming, 2012, 2014). This CI comparison method is not adjusted to control the family-wise error rate for multiple comparisons or making type I errors; however, not all scientists agree with the conservative approach of making adjustments for multiple comparisons (Rothman, 1990). To help readers see patterns in our data (variability, skewness, and scatter), we plotted the raw data with their $\mathrm{CI}$ as suggested by Drummond and Vowler (2011).

\section{Results}

\section{Climate}

The average daily air temperature during the mustard growth periods ranged from 3 to $13{ }^{\circ} \mathrm{C}$ in Year 1 and 3 to $16{ }^{\circ} \mathrm{C}$ in Year 2 but was usually greater than $5{ }^{\circ} \mathrm{C}$ (Fig. 2). Because of the shorter mustard growing period during Year $1(55 \mathrm{~d})$ vs. Year 2 (70 d), there were fewer growing degree days (GDDs) during Year 1 (384) than Year 2 (465). Five times more rainfall occurred during the mustard growing period in Year $1(30 \mathrm{~mm})$ than in Year $2(6 \mathrm{~mm})$. From strawberry transplanting to mustard planting date, the field received $24 \mathrm{~mm}$ of precipitation in Year 1 vs. only $11 \mathrm{~mm}$ in Year 2. For both years, there was little cumulative rainfall during the first $35 \mathrm{~d}$ after mustard seeding.

\section{Population density}

Despite relatively dry winter periods both years, the moisture in the furrows was adequate to stimulate germination and uniform mustard stands in the furrows (Fig. 3);

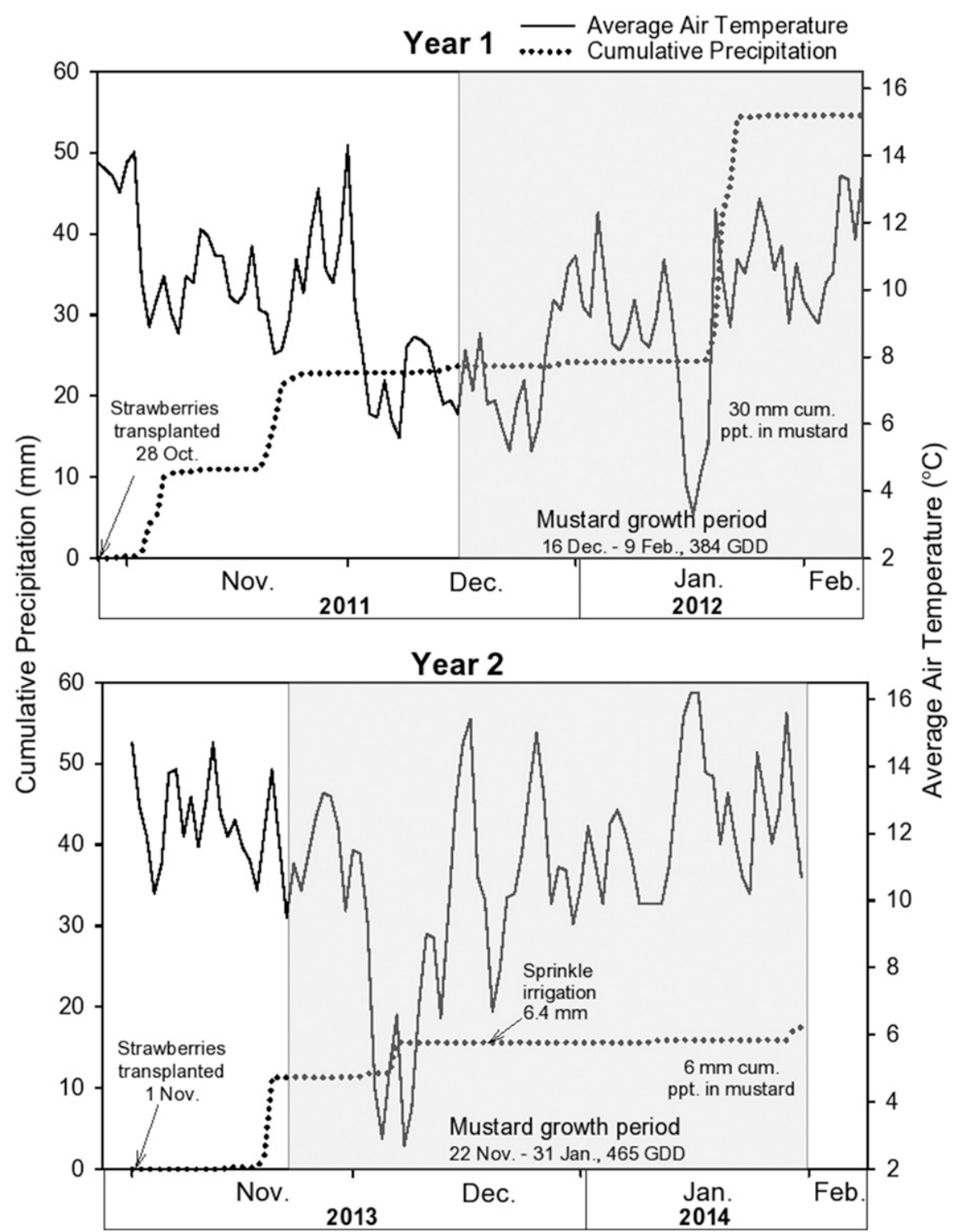

Fig. 2. Cumulative precipitation and average daily air temperatures from strawberry transplanting through the mustard cover crop growth period (shaded grey) during 2 years in Salinas, CA. Data were collected from the closest active station of the California Irrigation Management Information System; [South Salinas station no. 89 (Year 1), South Salinas station no. 214 (Year 2)]. The accumulated growing degree days (GDDs) during the mustard growth period were calculated with the single-sine method with a baseline threshold of $4{ }^{\circ} \mathrm{C}$ using the online calculator at the University of California Statewide Integrated Pest Management (http://www.ipm.ucdavis.edu). This calculator used temperature data from the Salinas municipal airport weather station that is $\approx 7 \mathrm{~km}$ from the experimental site. The X-axis on both plots runs from $28 \mathrm{Oct}$. to $9 \mathrm{Feb}$. The only irrigation that was applied to the cover crop occurred on 18 Dec. of Year 2 and was applied with a linear irrigation system.

this moisture was likely from preirrigation before bed shaping, rainfall, and movement of moisture from the drip-irrigated bed tops after strawberry transplanting. The average densities within each treatment were similar both years and ranged from 50 (Year 2) to 58 (Year 1) plants/m of furrow bottom at the $1 \times$ seeding rate and 157 (Year 1) to 167 (Year 2) plants $/ \mathrm{m}$ at the $3 \times$ seeding rate. The lack of overlap in the CI of the difference in densities within each year provides clear evidence that the seeding rate affected the mustard population densities. These densities were roughly 2.7 times $(172 \%)$ and 3.3 times $(232 \%)$ greater in the $3 \times$ than the
$1 \times$ seeding rate treatment during Years 1 and 2, respectively.

\section{Cover crop biomass production and plant height}

Mustard, oven-dry shoot biomass production ranged from an average of 35 to $66 \mathrm{~g} \cdot \mathrm{m}^{-1}$ furrow during Year 1 (Fig. 4A) to slightly higher levels (45 to $72 \mathrm{~g} \cdot \mathrm{m}^{-1}$ furrow) during Year 2 in the $1 \times$ and $3 \times$ seeding rates, respectively (Fig. 4B). The wider CIs during Year 1 indicates more variability than that during Year 2 . In both years, the $3 \times$ rate produced an average of at least $27 \mathrm{~g} \cdot \mathrm{m}^{-1}$ or $61 \%$ more shoot biomass than the $1 \times$ rate; the 


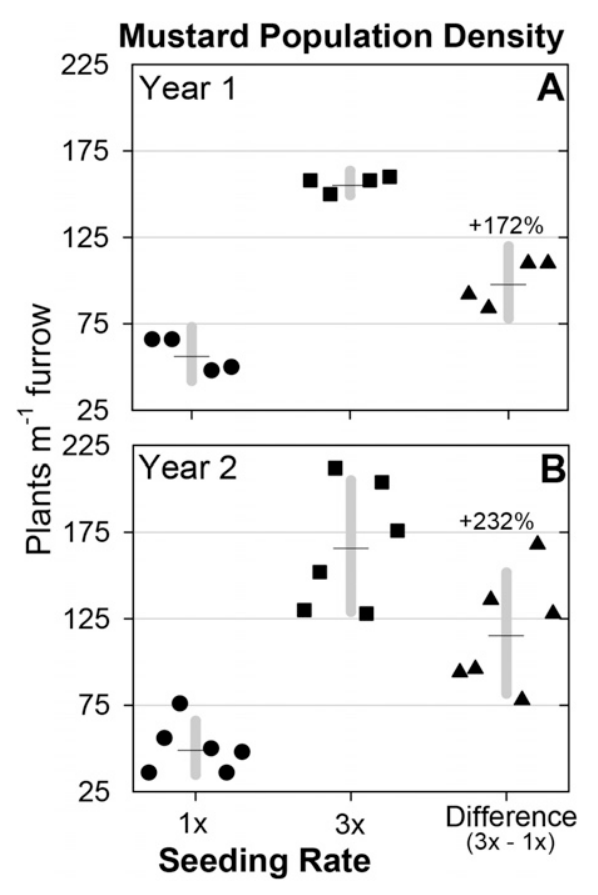

Fig. 3. Population densities of mustard cover crops planted in furrow bottoms of strawberry beds at two seeding rates and their difference during 2 years in Salinas, CA. Raw data points are shown in order of the replications (from left to right) as clusters around error bars that are $95 \%$ confidence intervals with the mean at the center horizontal line on the bar. The percentage above the difference is the average percentage change from the $1 \times$ to the $3 \times$ seeding rate. The population densities were determined at the end of the mustard growth period during Year 1 (9 Feb.) (A) and $55 \mathrm{~d}$ after planting (DAP), but during Year 2 (B) were determined at Dec. 9 (17 DAP).

scatter of the data points and the fact that zero was not within the CI of the difference between the $1 \times$ and $3 \times$ rates both years provide strong evidence that the higher rate was more productive.

The mustard had not begun to flower by the end of the cover crop growth period (early February) and the tips of the shoots were below the top of the bed during Year 1 and averaged $10 \mathrm{~cm}$ taller in the $3 \times$ treatment $(28 \mathrm{~cm})$ than in the $1 \times$ treatment $(18 \mathrm{~cm})$ (Fig. 5A). The mustard was taller during Year 2 than Year 1 and slightly exceeded the height of the bed top (Fig. 5B). By the end of the longer mustard growth period in Year 2 , the mustard shoots were also taller in the $3 \times$ than in the $1 \times$ seeding rate treatment, although overlap of the CI of the difference $(3 \times-1 \times)$ with zero provides little evidence of a treatment effect on the shoot height during Year 2.

The cover crop seeding rate had consistent effects on the height of the bud of the first true leaf (Fig. 6) that was $\approx 150 \%$ higher in the $3 \times$ than in the $1 \times$ seeding rate. The greater height of the first true leaf bud for both seeding rates during Year 1 than Year 2 may have been due to the later planting date and shorter growing period during Year 1, inclusion of the subcotyledon stem length
Mustard Shoot Biomass

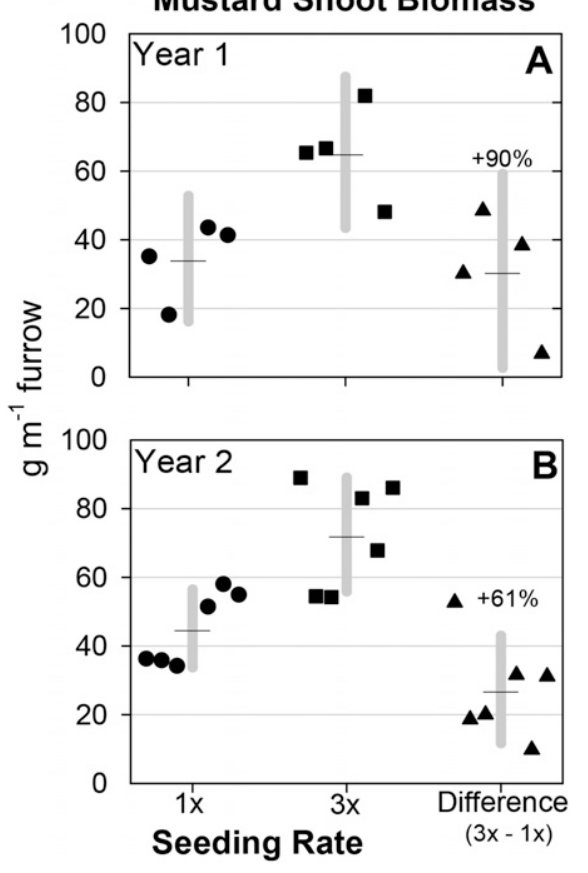

Fig. 4. Oven-dry shoot biomass of mustard cover crops in furrow bottoms of strawberry beds at two seeding rates and their difference during 2 years in Salinas, CA. Raw data points are shown in order of the replications (from left to right) as clusters around error bars that are $95 \%$ confidence intervals with the mean at the center horizontal line on the bar. The percentage above the difference is the average percentage change from the $1 \times$ to the $3 \times$ seeding rate. Biomass was determined on $9 \mathrm{Feb}$. (Year 1) (A) and 31 Jan. (Year 2) (B).

during Year 1 alone, or both; we estimate that the subcotyledon length was $\approx 1-2 \mathrm{~cm}$.

\section{Mustard nutrient concentration and residue quality}

Mustard shoot nutrient concentrations that were only measured during Year 1 ranged from $4 \%$ to $5.9 \% \mathrm{~N}, 0.48 \%$ to $0.58 \% \mathrm{P}$, and $1.9 \%$ to $2.5 \% \mathrm{~K}$ (Fig. $7 \mathrm{~A}-\mathrm{C}$ ) and were lower on average in the $3 \times$ than in the $1 \times$ seeding rate. However, $\mathrm{P}$ was the only nutrient where the CI of the difference did not include 0 , providing more evidence of true differences between rates. The C: $\mathrm{N}$ ratio of the shoots ranged from 6.6 to 9.9 and on average were slightly greater at the $3 \times$ than at the $1 \times$ rate, although the CI of the difference included 0 (Fig. 7D). Based on $\mathrm{N}$ concentrations and shoot biomass production, we estimate that aboveground $\mathrm{N}$ uptake by the mustard in the furrows would be $\approx 15$ and $25 \mathrm{~kg} \cdot \mathrm{ha}^{-1} \mathrm{~N}$ for the $1 \times$ and $3 \times$ seeding rates, respectively.

\section{Weed growth and suppression by mustard}

Weed growth was only measured during Year 2 and was dominated by burning nettle (Urtica urens L.) but also included other common winter weeds at this site such as shepherd's purse [Capsella bursa-pastoris

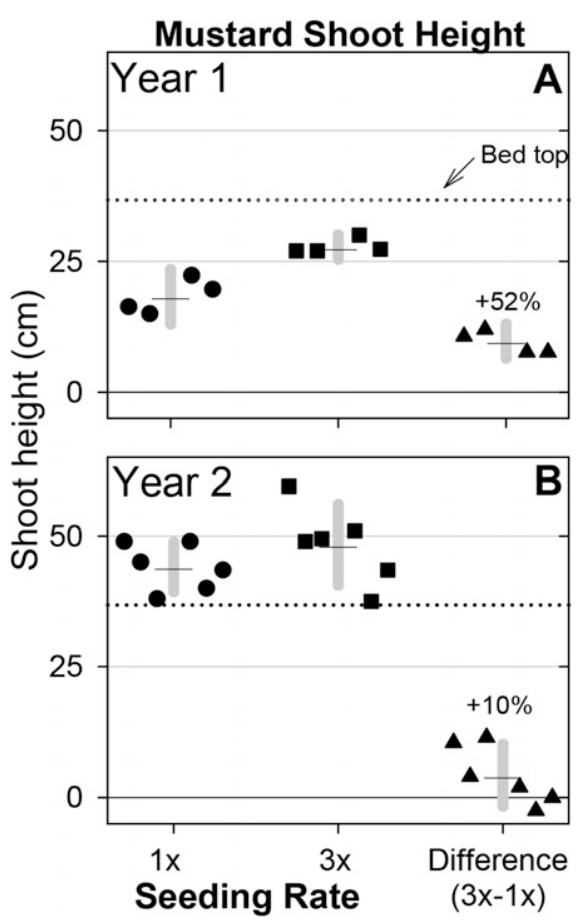

Fig. 5. Shoot height of mustard cover crops in furrow bottoms of strawberry beds at two seeding rates and their difference during 2 years in Salinas, CA. Raw data points are shown in order of the replications (from left to right) as clusters around error bars that are $95 \%$ confidence intervals with the mean at the center horizontal line on the bar. The percentage above the difference is the average percentage change from the $1 \times$ to the $3 \times$ seeding rate. Year 1 (A) measurements in each replication were the average of three randomly chosen plants from the soil surface to the top of the apical tip, whereas during Year 2 (B), the measurements for each replication were the average of the two tallest plants from the cotyledon mark to the top of the apical tip. The dotted horizontal line is the approximate height of the bed top $(37 \mathrm{~cm})$.

(L.) Medik.], little mallow (Malva parviflora L.), and common chickweed [Stellaria media (L.) Vill.]. Burning nettle shoots in the covercropped furrows immediately adjacent to the plastic mulch were often a similar height to the mustard shoots. Mustard and weeds shaded the entire furrow bottom in the cover-cropped furrows, but patches of bare soil were still visible in the no cover crop furrows. By the end of the mustard growth period, oven-dry weed biomass was highest on average with no cover crop $\left(38 \mathrm{~g} \cdot \mathrm{m}^{-1}\right.$ furrow), intermediate in the $1 \times$ rate $\left(28 \mathrm{~g} \cdot \mathrm{m}^{-1}\right)$, and lowest in the $3 \times$ rate $\left(23 \mathrm{~g} \cdot \mathrm{m}^{-1}\right)$ (Fig. $\left.8 \mathrm{~A}\right)$. The only situation where furrow cover cropping provided consistent improvement in weed suppression was in the comparison between the no cover crop treatment and the $3 x$ seeding rate, where there was a $40 \%$ decline in weed biomass (Fig. 8B). However, the same general pattern occurred in the comparison of the no cover crop treatment vs. $1 \times$ treatment for four of the six replications (Fig. 8B). 


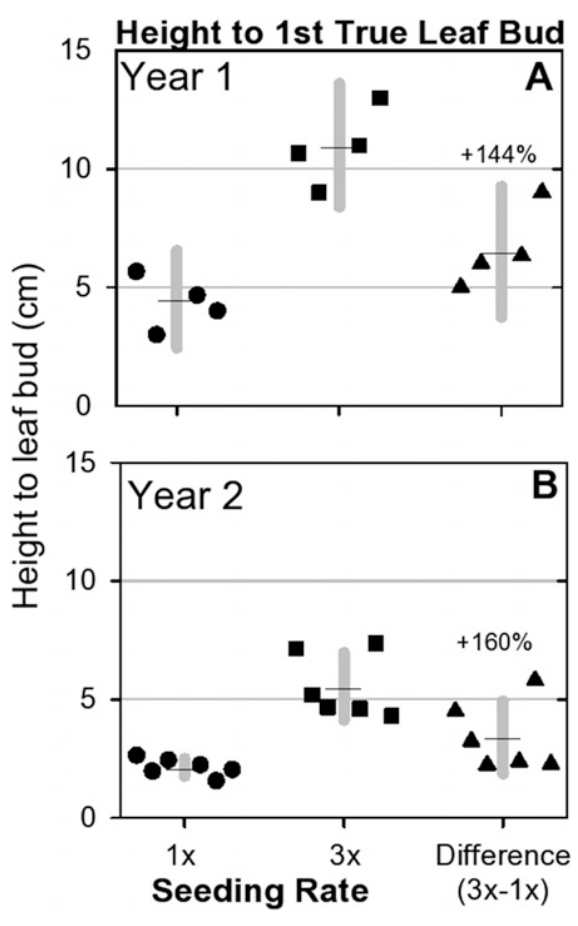

Fig. 6. Height to first true leaf bud of mustard cover crops in furrow bottoms of strawberry beds at two seeding rates and their difference during 2 years in Salinas, CA. Raw data points are shown in order of the replications (from left to right) as clusters around error bars that are $95 \%$ confidence intervals with the mean at the center horizontal line on the bar. The percentage above the difference is the average percentage change from the $1 \times$ to the $3 \times$ seeding rate. Year 1 measurements $(\mathbf{A})$ in each replication were the average of three randomly chosen plants from the soil surface to the first true leaf bud, whereas during Year 2 (B), the measurements for each replication were taken from the cotyledon leaf scar to the first true leaf bud.

Within the cover-cropped treatments, there was weak evidence of a negative, linear relationship between mustard shoot biomass and weed shoot biomass (Fig. 9). Total shoot biomass (weeds + cover crop) increased from an average in the no cover crop furrows $\left(39 \mathrm{~g} \cdot \mathrm{m}^{-1}\right)$ to the $1 \times$ rate $\left(73 \mathrm{~g} \cdot \mathrm{m}^{-1}\right)$ and the $3 \times$ rate $\left(95 \mathrm{~g} \cdot \mathrm{m}^{-1}\right)$ with weeds comprising $100 \%, 34 \%$, and $28 \%$ of this total in the no cover crop, $1 \times$, and $3 \times$ treatments, respectively (Fig. 10).

\section{Discussion}

Our study provides the first agronomic information on cover crop biomass production and weed suppression in furrows of plastic mulch-covered strawberry beds in California and thus builds on the previous extension report (Cahn et al., 2006a) that highlighted the value of cereal cover crops for reducing runoff and sediment loss in these systems. Such agronomic information will be helpful as we continue to refine and improve this practice and consider its practical implications (discussed later in the article). To our knowledge, this is the first study to evaluate a mustard or any nongrass cover crop in the

\section{Year 1}
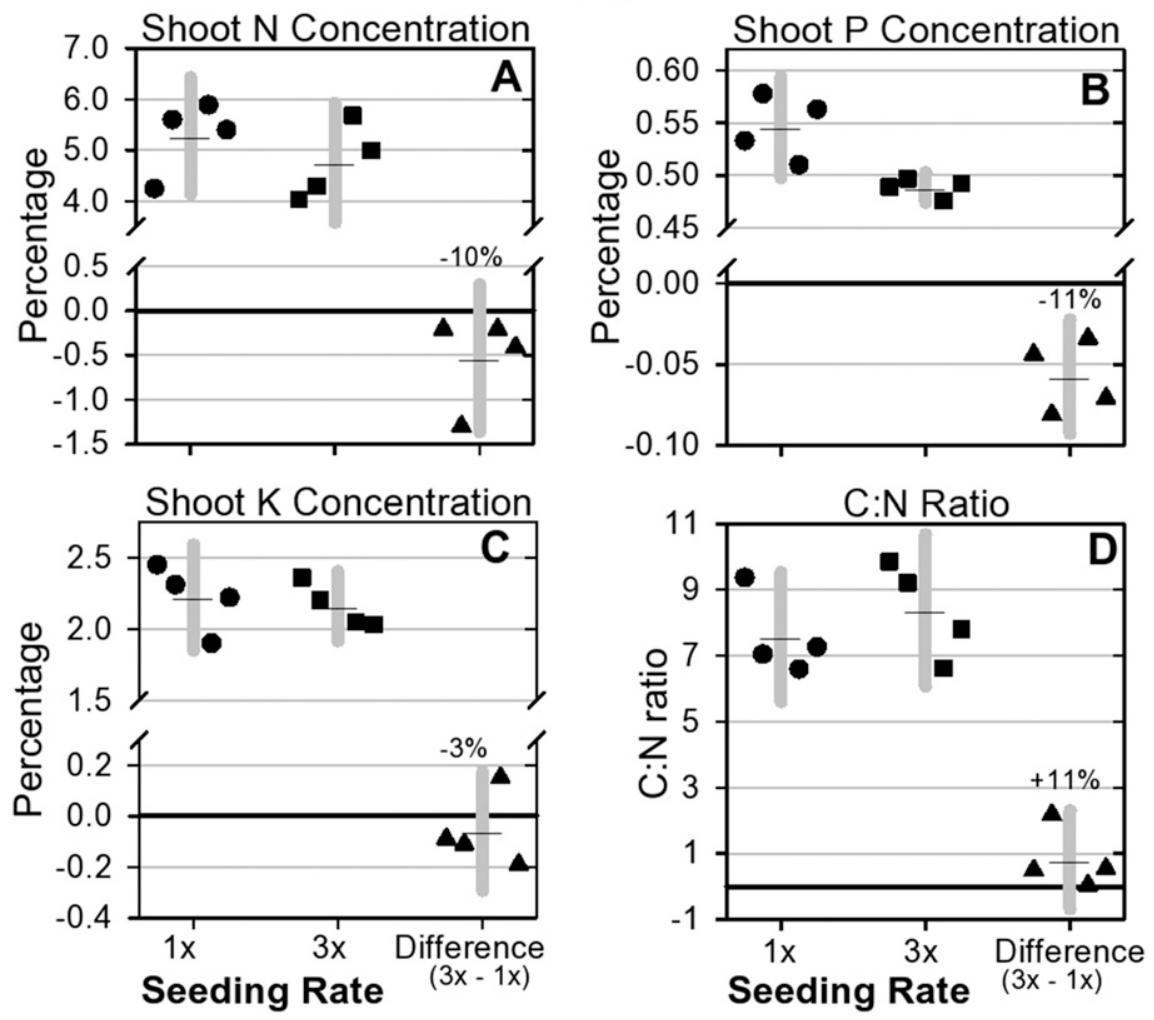

Fig. 7. Shoot nutrient concentrations $(\mathbf{A}-\mathbf{C})$ and $\mathrm{C}: \mathrm{N}$ ratio $(\mathbf{D})$ of mustard cover crops planted in furrow bottoms of strawberry beds at two seeding rates during Year 1 in Salinas, CA. Raw data points are shown in order of the replications (from left to right) as clusters around error bars that are $95 \%$ confidence intervals with the mean at the center horizontal line on the bar. The percentage above the difference is the average percentage change from the $1 \times$ to the $3 \times$ seeding rate.

furrows. We acknowledge that collecting weed data during Year 2 alone is a weakness of our study; however, the data do show clearly that large amounts of weed biomass can occur in cover-cropped furrows; this issue is discussed further in the Practical Implications section.

Many previous studies on cover crops and plastic mulch with vegetable systems have focused on cover crops as replacements for the plastic mulch (Abdul-Baki et al., 2002; Chellemi and Rosskopf, 2004; Duzy et al., 2014; Lilley and Sanchez, 2016; Maul et al., 2014; Tillman et al., 2015). In contrast, relatively little research has been carried out on ways to improve the sustainability of plastic-mulched systems by interplanting cover crops in furrows in other regions of the United States (Rice et al., 2001, 2007; Warren et al., 2015). The work by Rice et al. focused on rye (Secale cereale L.) to reduce erosion and pesticide loads in runoff in conventional tomato (Solanum lycopersicum L.) systems, whereas Warren et al. used a grass-legume living mulch to extend cover crop duration in organic broccoli (Brassica oleracea L. var. italica) and investigate competition dynamics.

Biomass production dynamic in furrows

Understanding biomass production by cover crops grown in furrows of cash crops is more complex than that by cover crops grown in the more typical solid-stand planting configuration. This is complex because 1) furrow cover crops may be planted into a slightly deeper layer in the soil profile caused by the bed shaping process, 2) the furrow may be shaded by the bed during parts of the day and receive reflected light from the plastic-mulched beds, 3 ) the furrow soil may be somewhat compacted because of tractor and foot traffic, 4) the furrow cover crop may be influenced by moisture and nutrient movement from irrigation water applied to the cash crop on the bed top, and 5) the furrow cover crop occupies a relatively small percentage of the field area. Nonetheless, it is interesting to compare the growth of the 'IdaGold' mustard cover crop from the present study with that of a mustard cover crop mixture dominated by 'IdaGold' growing as a solid stand in rotation with organic vegetables in the long-term organic systems study that occurred on another field at the same research farm (Brennan and Boyd, 2012a). In that study, 'IdaGold' was mixed with 'Pacific Gold' (Brassica juncea Czern.), but most of the biomass was produced by 'IdaGold'; the inability of 'Pacific Gold' to compete with 'IdaGold' in that mixture influenced our decision to use only 'IdaGold' in the present study. That cover crop mixture was planted in mid-October to early November, and shoot 

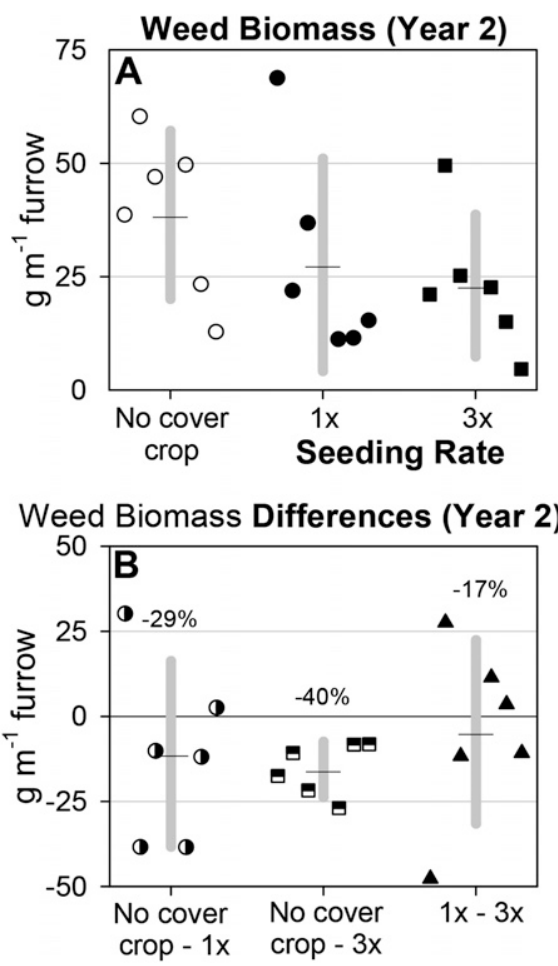

Fig. 8. Oven-dry shoot biomass of weeds in strawberry furrows with no cover crop vs. furrows planted with mustard cover crops at two seeding rates during Year 2 in Salinas, CA (A). Plot $\mathbf{B}$ illustrates the differences in weed biomass between the three treatments. The percentage above the differences in plot $\mathbf{B}$ is the average percentage change from the no cover crop to the $1 \times$, no cover crop to the $3 \times, 1 \times$ to the $3 \times$, respectively. Raw data points are shown in order of the replications (from left to right) as clusters around error bars that are $95 \%$ confidence intervals with the mean at the center horizontal line on the bar.

dry biomass averaged over several years was 2.3 and 5.6 Mg.ha ${ }^{-1}$ for December and February/March harvests, respectively. The $\mathrm{C}: \mathrm{N}$ ratio in the December harvest of that study was 9 , which is relatively similar to the mustard at the end of our study (Fig. 7D) and, thus, will be used for comparison of biomass in the furrow. On the basis of the furrow bottom area alone, we estimate that the mustard in the present study produced 1.11.5 and $2.1-2.4 \mathrm{Mg} \cdot \mathrm{ha}^{-1}$ biomass for the $1 \times$ and $3 \times$ seeding rates, respectively, in the furrow bottoms. Thus, the productivity of the $3 \times$ rate in the furrows is relatively similar to that of mustard by December $\left(2.3 \mathrm{Mg} \cdot \mathrm{ha}^{-1}\right)$ in a solid stand following vegetables, suggesting that mustard in the furrow microenvironment grew similarly to mustard in a solid stand. However, when considering the total area of the field (i.e., furrows and bed tops), biomass production by the furrow mustard would be considerably less because the furrows only make up approximately $25 \%$ of the field surface. Thus, even in the most productive situation (i.e., $3 \times$ rate during Year 2), shoot biomass production on the whole field basis was estimated at 0.55

\section{Mustard versus Weed Shoot Biomass (Year 2)}

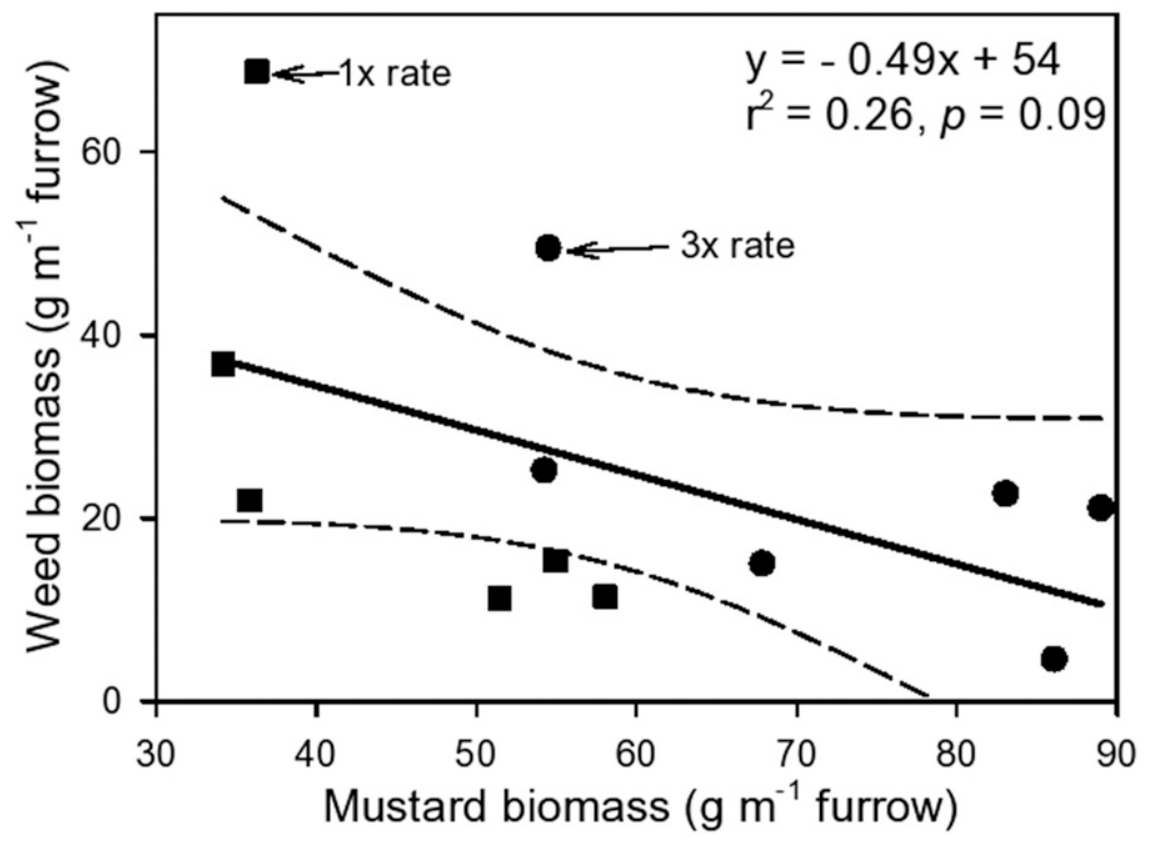

Fig. 9. Relationship between mustard cover crop shoot biomass and weed shoot biomass in strawberry furrows planted at two seeding rates $(1 \times$ and $3 \times)$ in Salinas, CA during Year 2 . The solid line is the fitted linear regression equation and the dashed lines are the $95 \%$ confidence interval bands.

$\mathrm{Mg} \cdot \mathrm{ha}^{-1}$, which is $\approx 25 \%$ of a solid stand mustard cover crop ended in December and $\approx 10 \%$ of the biomass of a solid-stand mustard cover crop grown for a full season (OctoberFebruary/March). As is discussed in the Practical Implications section, we are doubtful that these low levels of organic matter input affect soil health or quality.

\section{Cover crop seeding rate effects}

In California systems, the cover crop seeding rate can affect early-season biomass production and canopy development which in turn affects the growth and seed production of weeds under the cover crop canopy (Boyd et al., 2009; Brennan and Boyd, 2012a, 2012b; Brennan and Smith, 2005; Brennan et al., 2009, 2013). The population density of mustard in the furrows was reported per meter of furrow, but when converted to per unit area, it ranged from 189 to 513 plants $/ \mathrm{m}^{2}$ for Year 1 and 165 to 548 plants $/ \mathrm{m}^{2}$ for Year 2, in the $1 \times$ and $3 \times$ rates, respectively. These densities are similar to those of the mustard cover crop planted in a solid stand at $1 \times(182$ plants $\left./ \mathrm{m}^{2}\right)$ and $3 \times\left(492\right.$ plants $\left./ \mathrm{m}^{2}\right)$ seeding rates in the long-term study at this site (Brennan and Boyd, 2012a). In solid-stand cover crops, seeding rate typically influences biomass early in the growing season such that higher densities lead to more biomass, but gradually, the plants in the lower densities compensate by producing more biomass per plant, which eventually equals the biomass of higher rates (Boyd et al., 2009). In contrast to the vegetable study where seeding rate did not influence biomass by December (Brennan and Boyd, 2012a), mustard biomass in the furrows increased with seeding rate both years (Fig. 4A and B). We speculate that the cover crops planted at the lower rate in the furrows may not have had enough time to compensate for the lower densities which may explain the apparent inconsistency between the results of the present study and previous seeding rate studies in this region with solid-stand cover crops. However, the fact that seeding rate had the same overall effect on biomass in Years 1 and 2 that differed by 81 GDDs does not support this reasoning. Overall, our data suggest that the compensatory growth dynamics of cover crops in furrows is more delayed than that which occurs in solid-stand cover crops.

The general trend of $10 \%$ lower $\mathrm{N}$ concentrations of furrow cover crops in the higher seeding rate (Fig. 7A) agrees with previous research on the seeding rate effects on mustard, rye, and legume-rye cover crops (Brennan et al., 2013) and was likely caused by dilution of $\mathrm{N}$ with the greater biomass production at the higher rate. However, the more dramatic effect of seeding rate on $\mathrm{P}$ concentrations was not expected. Although the percent decline in $\mathrm{N}$ and $\mathrm{P}$ concentrations was similar (10 vs. 11) (Fig. 7A and B), the $\mathrm{CI}$ of this difference between rates for $\mathrm{P}$ did not overlap with 0 , providing stronger evidence of a true effect for $\mathrm{P}$ than for $\mathrm{N}$. We speculate that this difference may be related to nutrient movement and uptake that occurs with $\mathrm{N}$ by transpiration driven mass flow vs. the slower process of diffusion for P. It is likely that a portion of the $\mathrm{N}$ absorbed by the cover crop in the furrows came from leaching of $\mathrm{N}$ from the drip irrigated bed top, whereas movement of $\mathrm{P}$ from the bed top would be less likely. It is also important to note that 
Total Shoot Biomass (Weeds + Mustard)

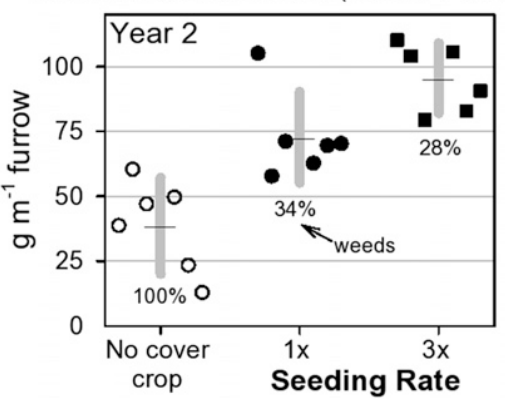

Fig. 10. Total shoot biomass from weeds and mustard cover crops in furrow bottoms of strawberry beds with no cover crop and two cover crop seeding rates during Year 2 in Salinas, CA. Raw data points are shown in order of the six replications (from left to right) as clusters around error bars that are $95 \%$ confidence intervals with the mean at the center horizontal line on the bar. The percentage below each data cluster is the average percentage of total shoot biomass from weeds.

available P levels in this sandy soil decline rapidly with depth (Brennan, unpublished data, 2017) and would, therefore, be more likely limited for cover crops planted in furrows that are accessing deeper and cooler soil layers than for solid-stand cover crops where the roots have access to the top soil.

\section{Practical implications of furrow cover cropping in strawberries}

1. Cover crop establishment in furrows. Establishing mustard in the furrow bottoms without irrigating the furrows was successful even during winters with relatively limited rainfall. Several factors may have contributed to this success, including 1) leftover moisture in the furrows from the preirrigation before bed shaping, 2) shedding of the relatively small amount of rainfall into the furrows from the plastic covered bed, and 3) movement of moisture from drip irrigation of the bed top into the furrows. In our experience with various cover crops in this region over several years, we have observed that mustards are perhaps the quickest to establish with limited moisture as long as their relatively small seeds are not planted too deeply.

2. Weed management in furrows. Weed management is critical with cover crops because research in this region has shown that cover cropping is one of the primary periods when large amount of weed seed production can occur (Boyd and Brennan, 2006; Brennan and Smith, 2005). Increasing the seeding rate is an effective way to suppress weed growth in solid-stand cover crops in California (Boyd et al., 2009; Brennan et al., 2009); however, contrary to our expectations, this approach was relatively ineffective at suppressing weeds in furrows during the 1 year when weed biomass was measured. The failure of the furrow cover crops to suppress weeds effectively was likely caused by the gap between the plastic mulch and the cover crop in the furrow center; planting cover crops closer to the plastic would have increased the risk of damaging the plastic when the cover crops were killed with the weed wacker. Ideally, weed biomass would account for an extremely small percentage (i.e., $<5 \%$ ) of the total biomass (cover crop and weeds) production and would be suppressed to the point that the weeds could not produce seeds. We do not consider the weed suppression provided by the cover crop at either seeding rate in our study to be adequate because the levels of weed biomass recorded would likely produce several thousand seeds per square meter and, thus, increase the weed seed bank. This speculation is based on our previous work (Brennan and Smith, 2005) where burning nettle produced 6010 seeds $/ \mathrm{m}^{2}$ from $\approx 65 \mathrm{~g}$ weed biomass $/ \mathrm{m}^{2}$. Similarly, an experiment in this region with other common winter weeds (i.e., shepherds purse and chickweed) reported that several hundred seeds per square meter were produced in cover crops with weed biomass as low as $17 \mathrm{~g} \cdot \mathrm{m}^{-2}$ (Boyd and Brennan, 2006). To address this challenge of weed management in furrow cover crops, a unique hoe with a thin, flexible, plastic mulch-friendly blade was developed (Brennan, 2015). This hoe allows growers to efficiently control small weeds along the edges of the furrow, adjacent to the plastic mulch. Once this first flush of weeds is killed, the cover crop is able to fill in the furrow bottom and provide good weed suppression in many cases. Given the potential for large amounts of weed biomass production and, hence, weed seed production in furrow cover crops even when planted at high seeding rates, we highly recommend hand weeding soon after cover crop emergence.

3. Strawberry yields. Furrow cover crops could potentially impact the yield of strawberries through below- or aboveground competition. A study with cover crops between plastic-mulched broccoli beds found lower marketable yields in broccoli with cover crops in the furrows (Warren et al., 2015), but in that case, the living mulch cover crop grew alongside the broccoli up to broccoli harvest and was repeatedly mowed. However, preliminary data indicate that strawberry yields are unaffected by well-managed mustard cover crops in furrows (Brennan, unpublished data, 2014). The commercialscale strawberry fields where the trial occurred were among the top yielding fields in this region for the San Juan variety of strawberries, which suggests that the covercropped furrows did not reduce yields (R. Fuentes, personal communications, 201114). As a result, furrow cover cropping is now a required practice in the commercial-scale production that occurs annually at the USDA-ARS organic research farm in Salinas. The potential for belowground competition between mustard and the strawberries is unlikely, given that the bed tops were $\approx 37$ $\mathrm{cm}$ above the furrow bottom. Furthermore, aboveground competition for light in our study was also unlikely because the cover crops were killed before they were shading the strawberry plants on the bed top.
Although the cover crops were slightly above the bed top during Year 2, the mustard canopy was highest in the furrow center and the canopy edges adjacent to the plastic were about at the same height as the bed top. Although the data suggest that the risk of shading of the strawberries by the cover crops is greater when the cover crops are planted at a higher seeding rate, the data also indicate that the differences in cover crop height due to seeding rate declined over time. For example, during Year 1 when the cover crop accumulated fewer GDDs, the mustard was $52 \%$ taller in the $3 \times$ than in the $1 \times$ rate, whereas this difference was only $10 \%$ during Year 2 when the cover crops were taller overall, accumulated more GDDs, and were closer to the bed top (Fig. 5).

4. Cover crop termination. Killing mustard cover crops in furrows was effective using a string trimmer to mow the cover crops in February. However, this required careful attention by the operator of the string trimmer to avoid hitting the plastic mulch on the sides of adjacent beds that are closest near the bottom of the furrow. One reason we evaluated seeding rate was to determine if it affected the height of the first true leaf bud from which the mustard could potentially regrow following mowing. As expected, planting at the higher density increased the height of the first true leaf bud, which would potentially increase the height at which the cover crops would need to be cut to prevent regrowth. However, despite the differences in the height of the mustard at the two seeding rates, regrowth of the mustards was not observed in our study.

5. Decomposition dynamics of the killed residue. Given the low C:N ratio (7 to 9) of the mustard shoots by February, this material would be expected to decompose relatively quickly if incorporated into the furrow bottoms. This appears to have been the case in our study where the cover crops were incorporated into the furrow with a narrow strip tiller that helped to smooth out the furrow bottom in preparation for harvesting. Smooth furrow bottoms can facilitate easy movement of the single-wheeled strawberry harvest carts that are pushed along by the people picking the strawberries.

6. Soil health or quality. Although growing cover crops annually that produce more than $5 \mathrm{Mg} \cdot \mathrm{ha}^{-1}$ shoot biomass in intensive vegetable systems in the Salinas Valley can improve soil health over time (Brennan and Acosta-Martinez, 2017), it is unlikely that the relatively low biomass production levels of the mustard cover crops in the strawberry furrows described here would have much, if any, lasting positive impact on soil health parameters such as soil organic matter. For comparison, consider that the highest level of furrow mustard biomass production in our study $\left(75 \mathrm{~g} \cdot \mathrm{m}^{-1}\right.$ furrow, Fig. 4B; which is $\approx 0.55 \mathrm{Mg} \cdot \mathrm{ha}^{-1}$ ) is less than the amount of postharvest shoot residue returned to the soil following onions in the San Joaquin Valley of California (Mitchell et al., 1999). By contrast, in that study, broccoli postharvest, 
oven-dried shoot residue returned to the soil was $7.3 \mathrm{Mg} \cdot \mathrm{ha}^{-1}$, which is comparable to shoot biomass production of a solid-stand, mature winter cover crop like rye or a legume-rye mixture (Brennan and Boyd, 2012a). Research in agronomic systems has determined that $5-6 \mathrm{Mg} \cdot \mathrm{ha}^{-1}$ of the plant residue needs to be returned to the soil annually to maintain soil organic matter levels (Larson et al., 1972; Rasmussen et al., 1980); similar studies in high-input horticultural crops have not been carried out, but plant residue needed to maintain soil organic matter may be even greater, given the relatively high levels of tillage and fertilizer inputs in many horticultural systems. We point out the relatively low biomass production and thus low-potential soil health benefits of cover cropping in strawberry furrows not to diminish the value of this practice to provide important services (i.e., scavenging $\mathrm{N}$ and reducing sediment loss) but to highlight that furrow cover crops should not be considered a replacement of more typical solid-stand, high biomassproducing cover crops.

7. Nitrate leaching. Cover cropping in strawberry furrows has the potential to reduce $\mathrm{N}$ leaching because the cover crops accumulated considerable $\mathrm{N}$ in their shoot residue, particularly at the higher seeding rate $\left(25 \mathrm{~kg} \cdot \mathrm{ha}^{-1} \mathrm{~N}\right)$. Given that the furrow mustard only occupied $\approx 25 \%$ of the field area, this level of $\mathrm{N}$ scavenging is similar to mustard $\mathrm{N}$ uptake of $111 \mathrm{~kg} \cdot \mathrm{ha}^{-1}$ by December in solidstand cover crops (Brennan and Boyd, $2012 b)$. However, it is important to highlight that the $\mathrm{N}$ scavenged in the cover-cropped furrows could be subject to subsequent leaching in spring rains if the high $\mathrm{N}$ content residue decomposed quickly after the cover crop was mowed. Thus, we consider improved water quality in runoff to be the primary potential strength of cover-cropped strawberry furrows. Nitrate leaching primarily from agriculture in the Salinas Valley is a major problem that threatens the drinking water supply (Harter et al., 2012) but is an issue that can be reduced by the use of nonlegume cover crops such as mustard (Hartz, 2006; Jackson et al., 1993a, 1993b).

\section{Conclusion and future research}

This study provides novel information on cover crop biomass production and weed suppression by mustard cover crops planted in the furrows of plastic mulch-covered strawberry beds in California. The cover crop established well when planted into the furrows in late November to mid-December even during relatively dry winter periods and reached the bed top by early February. Increasing the seeding rate increased cover crop biomass production, shoot height, $\mathrm{N}$ uptake, and weed suppression. The study provides growing evidence that cover cropping in strawberry furrows is a best management practice that has the potential to improve the sustainability of organic and conventional strawberry production systems in California. In future studies with vegetated strawberry furrows, it would be useful to evaluate effects on strawberry yields and compare the ability of mustards vs. cereal cover crops to affect $\mathrm{N}$ leaching and runoff. Although cover cropping in vegetable production systems complicates management because of the potential production of large amounts of biomass (Brennan, 2017), cover cropping in otherwise bare furrows of strawberries has a relatively low opportunity cost and, thus, the potential to become a widely adopted practice, particularly if it helps growers to solve problems such as weed management in furrows and runoff.

\section{Literature Cited}

Abdul-Baki, A.A., J.R. Teasdale, R.W. Goth, and K.G. Haynes. 2002. Marketable yields of freshmarket tomatoes grown in plastic and hairy vetch mulches. HortScience 37:878-881.

Anderson, D.R., K.P. Burnham, and W.L. Thompson. 2000. Null hypothesis testing: Problems, prevalence, and an alternative. J. Wildl. Mgt. 64:912923.

Association of Analytical Communities. 1997. AOAC official method 972.43, microchemical determination of carbon, hydrogen, and nitrogen, automated method, in official methods of analysis of AOAC international. 16th ed. Chapter 12, p. 5-6. AOAC Intl., Arlington, VA. $<$ http://www.aoac.org/about/aoac.htm $>$.

Boyd, N.S. and E.B. Brennan. 2006. Weed management in a legume-cereal cover crop with the rotary hoe. Weed Technol. 20:733-737.

Boyd, N.S., E.B. Brennan, R.F. Smith, and R. Yokota. 2009. Effect of seeding rate and planting arrangement on rye cover crop and weed growth. Agron. J. 101:47-51.

Brennan, E.B. 2015. How to make an inexpensive hoe for efficient weeding, 'Recycle Strap Hoe'. 5 Mar. 2018. <www.youtube.com/watch? $\mathrm{v}=\mathrm{woHNgHkbWzA}>$

Brennan, E.B. 2017. Can we grow organic or conventional vegetables sustainably without cover crops? HortTechnology 27:151-161.

Brennan, E.B. and V. Acosta-Martinez. 2017. Cover cropping frequency is the main driver of soil microbial changes during six years of organic vegetable production. Soil Biol. Biochem. 109:188-204.

Brennan, E.B. and N.S. Boyd. 2012a. Winter cover crop seeding rate and variety affects during eight years of organic vegetables: I. Cover crop biomass production. Agron. J. 104:684-698.

Brennan, E.B. and N.S. Boyd. 2012b. Winter cover crop seeding rate and variety affects during eight years of organic vegetables: II. Cover crop nitrogen accumulation. Agron. J. 104:799-806.

Brennan, E.B., N.S. Boyd, and R.F. Smith. 2013. Winter cover crop seeding rate and variety affects during eight years of organic vegetables: III. Cover crop residue quality and nitrogen mineralization. Agron. J. 105:171-182.

Brennan, E.B., N.S. Boyd, R.F. Smith, and P. Foster. 2009. Seeding rate and planting arrangement effects on growth and weed suppression of a legume-oat cover crop for organic vegetable systems. Agron. J. 101:979-988.

Brennan, E.B. and R.F. Smith. 2005. Winter cover crop growth and weed suppression on the central coast of California. Weed Technol. 19:1017-1024.

Cahn, M., M. Bolda, and R. Smith. 2006a. Winter cover crops for reducing storm run-off and protecting water quality in strawberries, p. 2-4.
Crop notes. Univ. California Coop. Ext., Monterey County, CA. 5 Mar. 2018. <http://cemonterey. ucanr.edu/newsletters/November-December, 200632272.pdf>.

Cahn, M., R. Smith, and A. Young. 2006b. Evaluation of practices for controlling strom run-off from vegetable fields. 8 Feb. 2016. <http:// cemonterey.ucanr.edu/newsletters/NovemberDecember,_200632272.pdf>.

California Environmental Protection Agency. Irrigated lands regulatory program. 5 Mar. 2018. $<$ http://www.waterboards.ca.gov/water_issues/ programs/agriculture/>

Campbell, K.G., Y.M. Thompson, S.O. Guy, M. McIntosh, and B. Glaz. 2015. Is, or is not, the two great ends of Fate: Errors in agronomic research. Agron. J. 107:718-729.

Chellemi, D.O. and E.N. Rosskopf. 2004. Yield potential and soil quality under alternative crop production practices for fresh market pepper. Renew. Agr. Food Syst. 19:168-175.

Cumming, G. 2012. Understanding the new statistics: Effect sizes, confidence intervals, and meta-analysis. Routledge, New York, NY.

Cumming, G. 2014. There's life beyond .05. 5 Mar 2018. <http://www.psychologicalscience.org/ index.php/publications/observer/2014/march14/theres-life-beyond-05.html $>$.

Drummond, G.B. and S.L. Vowler. 2011. Show the data, don't conceal them. Clin. Expt. Pharmacol. Physiol. 38:287-289.

Duzy, L.M., T.S. Kornecki, K.S. Balkcom, and F.J. Arriaga. 2014. Net returns and risk for cover crop use in Alabama tomato production. Renew. Agr. Food Syst. 29:334-344.

Fidler, F., M.A. Burgman, G. Cumming, R. Buttrose, and N. Thomason. 2006. Impact of criticism of null-hypothesis significance testing on statistical reporting practices in conservation biology. Conserv. Biol. 20:1539-1544.

Harter, T., J.R. Lund, J. Darby, G.E. Fogg, R. Howitt, K.K. Jessoe, G.S. Pettygrove, J.F. Quinn, J.H. Viers, D.B. Boyle, H.E. Canada, N. DeLaMora, K.N. Dzurella, A. Fryjoff-Hung, A.D. Hollander, K.L. Honeycutt, M.W. Jenkins, V.B. Jensen, A.M. King, G. Kourakos, D. Liptzin, E.M. Lopez, M.M. Mayzelle, A. McNally, J. Medellin-Azuara, and T.S. Rosenstock. 2012. Addressing nitrate in California's drinking water with a focus on Tulare Lake basin and Salinas Valley groundwater, p. 8 In: Report for the State Water Resources Control Board report to the legislature. Ctr. Watershed Sci., Univ. California, Davis, CA. 5 Mar. 2018. $<$ http://groundwaternitrate.ucdavis.edu/files/ 138958.pdf>

Hartz, T.K. 2006. Vegetable production best management practices to minimize nutrient loss. HortTechnology 16:398-403.

Hubbard, R. and R.M. Lindsay. 2008. Why P values are not a useful measure of evidence in statistical significance testing. Theory Psychol. 18:69-88.

Jackson, L.E., L.J. Wyland, J.A. Klein, R.F. Smith, W.E. Chaney, and S. Koike. 1993a. Winter cover crops can decrease soil nitrate, leaching potential. Calif. Agr. 47:12-15.

Jackson, L.E., L.J. Wyland, and L.J. Stivers. 1993b. Winter cover crops to minimize nitrate losses in intensive lettuce production. J. Agr. Sci. 121:55-62.

Kirk, R.E. 1996. Practical significance: A concept whose time has come. Educ. Psychol. Meas. 56:746-759.

Lambdin, C. 2012. Significance tests as sorcery: Science is empirical-significance tests are not. Theory Psychol. 22:67-90.

Larson, W.E., Y.B. Morachan, C.E. Clapp, and W.H. Pierre. 1972. Effects of increasing amounts of organic residues on continuous 
corn. 2. Organic carbon, nitrogen, phosphorus, and sulfur. Agron. J. 64:204-208.

Lilley, J.M. and E.S. Sanchez. 2016. The potential of strip tillage and rowcovers for organic cucurbit production. HortTechnology 26:628-636.

Loftus, G.R. 1996. Psychology will be a much better science when we change the way we analyze data. Curr. Dir. Psychol. Sci. 5:161-171.

Maul, J.E., J.S. Buyer, R.M. Lehman, S. Culman, C.B. Blackwood, D.P. Roberts, I.A. Zasada, and J.R. Teasdale. 2014. Microbial community structure and abundance in the rhizosphere and bulk soil of a tomato cropping system that includes cover crops. Appl. Soil Ecol. 77:42-50.

Mitchell, J., T. Hartz, S. Pettygrove, D. Munk, D. May, F. Menezes, J. Diener, and T. O’Neill. 1999. Organic matter recycling varies with crops grown. Calif. Agr. 53:37-40.

Monterey County Agricultural Commissioner. 2016. Monterey County crop report 2016. 30 June 2017. <http://www.co.monterey.ca.us/ Home/ShowDocument?id=27601>.

Mountjoy, D.C. 2012. Erosion and sediment management strategies for organc strawberries, p. 55-63. In: S.T. Koike, C.T. Bull, M. Bolda, and O. Daugovish (eds.). Organic strawberry production manual. Univ. California, Richmond, CA.
Nakagawa, S. and I.C. Cuthill. 2007. Effect size, confidence interval and statistical significance: A practical guide for biologists. Biol. Rev. Camb. Philos. Soc. 82:591-605.

Rasmussen, P.E., R.R. Allmaras, C.R. Rohde, and N.C. Roager. 1980. Crop residue influences on soil carbon and nitrogen in a wheat-fallow system. Soil Sci. Soc. Amer. J. 44:596-600.

Rice, P.J., C.J. Hapeman, L.L. McConnell, A.M Sadeghi, J.R. Teasdale, C.B. Coffman, G.W. McCarty, A.A. Abdul-Baki, and J.L. Starr. 2007. Evaluation of vegetable production management practices to reduce the ecological risk of pesticides. Environ. Toxicol. Chem. 26:2455-2464.

Rice, P.J., J.A. Harman-Fetcho, J.R. Teasdale, A.M. Sadeghi, L.L. McConnell, C.B. Coffman, R.R. Herbert, L.P. Heighton, and C.J. Hapeman. 2004. Use of vegetative furrows to mitigate copper loads and soil loss in runoff from polyethylene (plastic) mulch vegetable production systems. Environ. Toxicol. Chem. 23:719-725.

Rice, P.J., L.L. McConnell, L.P. Heighton, A.M. Sadeghi, A.R. Isensee, J.R. Teasdale, A.A. Abdul-Baki, J.A. Harman-Fetcho, and C.J. Hapeman. 2001. Runoff loss of pesticides and soil: A comparison between vegetative mulch and plastic mulch in vegetable production systems. J. Environ. Qual. 30:1808-1821.

Rothman, K.J. 1990. No adjustments are needed for multiple comparisons. Epidemiology 1:43-46.

Santa Cruz County Agricultural Commissioner. 2016. Santa Cruz County crop report 2016. 27 Sept. 2017. <http://www.agdept.com/Portals/ $10 /$ pdf $/ 2016 \% 20$ Crop $\% 20$ Report $\% 20$ for $\%$ 20Webpage.pdf?ver=2017-09-19-114303250\& timestamp $=1505853515815>$.

Smith, R., E.B. Brennan, and M. Bolda. 2015. Managing cover crops on strawberry furrow bottoms. Agr. Natural Resources Blog, Univ. California. 5 Mar. 2018. <http://ucanr.edu/blogs/ blogcore/postdetail.cfm?postnum $=19929>$.

Strand, L.L. 2008. Integrated pest management for strawberries. Univ. California, Oakland, CA.

Tillman, J., A. Nair, M. Gleason, and J. Batzer. 2015. Rowcovers and strip tillage provide an alternative to plasticulture systems in summer squash production. HortScience 50:17771783.

Warren, N.D., R.B. Smith, and R.G. Sideman. 2015. Effects of living mulch and fertilizer on the performance of broccoli in plasticulture. HortScience 50:218-224. 